\title{
Risks of sea level rise to disadvantaged communities in the United States
}

\author{
Jeremy Martinich • James Neumann • Lindsay Ludwig • \\ Lesley Jantarasami
}

Received: 30 August 2011 / Accepted: 27 December 2011 / Published online: 4 February 2012

(C) The Author(s) 2011. This article is published with open access at Springerlink.com

\begin{abstract}
Climate change and sea level rise (SLR) pose risks to coastal communities around the world, but societal understanding of the distributional and equity implications of SLR impacts and adaptation actions remains limited. Here, we apply a new analytic tool to identify geographic areas in the contiguous United States that may be more likely to experience disproportionate impacts of SLR, and to determine if and where socially vulnerable populations would bear disproportionate costs of adaptation. We use the Social Vulnerability Index (SoVI) to identify socially vulnerable coastal communities, and combine this with output from a SLR coastal property model that evaluates threats of inundation and the economic efficiency of adaptation approaches to respond to those threats. Results show that under the mid-SLR scenario $(66.9 \mathrm{~cm}$ by 2100 ), approximately $1,630,000$ people are potentially affected by SLR. Of these, $332,000(\sim 20 \%)$ are among the most socially vulnerable. The analysis also finds that areas of higher social vulnerability are much more likely to be abandoned than protected in response to SLR. This finding is particularly true in the Gulf region of the United States, where over $99 \%$ of the most socially vulnerable people live in areas unlikely to be protected from inundation, in stark contrast to the least socially vulnerable group, where only $8 \%$ live in areas unlikely to be protected. Our results demonstrate the importance of considering the equity and environmental justice implications of SLR in climate change policy analysis and coastal adaptation planning.
\end{abstract}

Keywords Adaptation - Climate change - Coast · Environmental justice $\cdot$ Sea level rise $\cdot$ Social

J. Martinich $(\bowtie) \cdot$ L. Jantarasami

Climate Change Division, U.S. Environmental Protection Agency, 1200 Pennsylvania Ave, NW,

MC6207-J, Washington, DC 20460, USA

e-mail: martinich.jeremy@epa.gov

J. Neumann · L. Ludwig

Industrial Economics Incorporated, Cambridge, MA, USA 


\section{Background and motivation}

Climate change and sea level rise (SLR) will pose increasing risks to coastal communities in the future (Karl et al. 2009). The combined impact of thermal expansion of ocean water and ice loss from glaciers and small ice caps is likely to raise sea level by at least 60 centimeters (cm) by 2100 (NRC 2011). Some studies indicate that ice loss from the Greenland and Antarctica ice sheets could contribute an additional $30 \mathrm{~cm}$ of SLR by the end of the century (NRC 2011). Regional and local factors (e.g., changes in land elevation) will influence future relative SLR for specific coastlines around the world. For example, in the United States (U.S.), a $60 \mathrm{~cm}$ rise in global (eustatic) sea level by the end of this century would result in a relative SLR of $70 \mathrm{~cm}$ at New York City, $88 \mathrm{~cm}$ at Hampton Roads, Virginia, and $107 \mathrm{~cm}$ at Galveston, Texas (Karl et al. 2009).

The populations that reside in coastal communities will be faced with three general options in response to SLR risks: 1) hold back the sea, 2) accommodate a receding shoreline, or 3 ) retreat (CCSP 2009). Each of these options differ in magnitude and type of economic costs. The Intergovernmental Panel on Climate Change (IPCC) concluded that the consequences of SLR, including protection costs, will likely be greater for developing countries relative to those for developed countries, but noted that to date, the majority of quantitative SLR impact studies have focused on developed countries given limited data availability in many developing countries (Nicholls et al. 2007). For the U.S., a number of studies have sought to quantify and value the future impacts and adaptation costs of SLR to coastal populations (e.g., Yohe et al. 1996; Titus et al. 1991; Yohe 1990) and in Europe (Hinkel et al. 2010). Recent projections for the contiguous U.S. (i.e., lower 48 states) suggest more than $\$ 230$ billion in total undiscounted costs by 2100 under a mid-range $(68 \mathrm{~cm})$ SLR scenario (Neumann et al. 2010b).

None of these national-scale studies have focused on or quantitatively analyzed how SLR risks and the costs of likely adaptation responses will be distributed across various socioeconomic populations along the coast. Two key questions arise when considering and assessing the distributional and equity implications of SLR and likely adaptation actions. First, do the coastal communities whose elevations are vulnerable to SLR tend to be inhabited more frequently by underserved and disadvantaged communities? This line of inquiry seeks to understand whether lower income, minority populations are more likely to inhabit areas that contain greater exposure to environmental risks compared to the general population. Secondly, if adaptation responses to coastal risks are likely to be based on some measure of economic efficiency, with more valuable land being more likely to be protected, as suggested by previous studies (Yohe 1990; Nicholls et al. 2008), then are socially vulnerable communities located in high-risk areas for inundation more likely to experience disproportionally adverse consequences? In other words, are these communities more likely to be compelled to abandon their residences because coastal planners and governments could determine, in the face of scarce resources to improve adaptive capacity, that it is economically inefficient or cost-prohibitive to protect these localities?

Illustrating the policy relevance and timeliness of addressing these questions, recent U.S. federal efforts have identified the need to assess the environmental justice ${ }^{1}(E J)$ implications of climate change. For example, in August 2011, 17 U.S. federal agencies signed the Memorandum of Understanding on Environmental Justice and Executive Order 12898

\footnotetext{
${ }^{1}$ In this context, environmental justice is defined as the fair treatment and meaningful involvement of all people regardless of race, color, national origin, or income with respect to the development, implementation, and enforcement of environmental laws, regulations, and policies.
} 
(MOU 2011). With respect to climate change impacts, this agreement requires U.S. federal agencies to identify and address "any disproportionately high and adverse human health or environmental effects of its programs, policies and activities on minority populations and low-income populations."

A few empirical studies have focused on analyzing the EJ implications of SLR-related risks, specifically at local and regional scales. Rygel et al. (2006) developed an index of storm surge vulnerability that included social vulnerability indicators, and Kleinosky et al. (2006) applied this coastal hazards index in a case study of Hampton Roads, Virginia. Clark et al. (1998) examined the distribution of social and physical vulnerability of coastal residents to storm surge hazards in the city of Revere, Massachusetts, using indicators derived from U.S. census data. However, in all of these studies the cost of adaptive response actions - a critical consideration in determining the ability of a coastal community to respond to coastal risks - was not among the variables considered in their analyses.

The serious risks posed by SLR, the potential for socially vulnerable populations to be disproportionally impacted by these risks, and the prioritization of these issues by U.S. policy-makers underscore the need for flexible analytical frameworks that can be applied comprehensively across large regions. The primary objective of our research is to apply one such framework to identify socio-economic populations that may be more likely to experience disproportionate impacts of SLR in the contiguous U.S., as well as those communities that would bear disproportionate costs in order to effectively respond to the threats.

\section{Methods - a framework for assessing environmental justice implications of SLR}

We employ a flexible analytical framework that can be applied at international, national, regional, and local scales, and can accommodate varying levels of data availability and resolution. Our approach involves three main steps: (1) assessing the social vulnerability and demographic characteristics of populations in the coastal zone; (2) estimating SLR impacts and responses in the study area; and (3) comparing these results spatially. We identified disadvantaged communities along the contiguous U.S. coastline (step 1) by calculating Social Vulnerability Index (SoVI) scores according to the methods outlined in Cutter et al. (2003) for each coastal census tract. As described in Sections 2.1 and 2.2 below, we used the SoVI index to analyze a large set of socio-economic and demographic variables; however, demographic indicators such as wealth and race can be used in the absence of detailed data. We then applied an existing analytical model (step 2) previously developed by EPA and collaborators called the SLR national coastal property model (NCPM), for which Neumann et al. (2010a, b) have documented the full methodological details. We assessed low, mid, and high SLR scenarios to identify areas at risk and the economically efficient adaptation response (abandon, protect, or nourish) for each of these areas. For developing nation coastlines, many of which lack detailed elevation, property value, and protection cost estimates, global coastal risk models, such as DIVA (Vafeidis et al. 2008), could be employed to assess the potential impacts of SLR. Lastly, we spatially compared the social vulnerability and SLR risk information (step 3) in a Geographic Information System (GIS) to determine if socially vulnerable communities are likely to experience disproportionate impacts of SLR and/or bear a disproportionate level of the costs in order to effectively respond to the threat. While using a GIS offers substantial advantages, particularly over larger geographic areas, simpler methods can be employed to compare SLR risk and social vulnerability information. For example, over smaller areas, spreadsheet based evaluations are possible, using data compiled for gridded areas or for political or census divisions. 
2.1 Existing literature on estimating social vulnerability in the U.S.

A number of indices or models exist that seek to identify disadvantaged communities. We review several here that are most relevant to our objective, but this paper does not attempt to review, as others have, the available literature on general social vulnerability (Rygel et al. 2006; Cutter 1996; Dow 1992). In most cases, EJ indices incorporate environmental risk factors (e.g., health risks), as well as social vulnerability factors (e.g., income, age).

Moss et al. (2001) developed the Vulnerability-Resilience Indicator Model which aggregates 17 social and environmental variables into sectors, then into sensitivity and adaptive capacity values, and finally into a resilience index. The Environmental Justice Screening Method was developed by Poastor et al. (2009) for the California Air Resources Board. This method is designed to identify and map cumulative impacts and vulnerability at the neighborhood-level using a comprehensive set of 24 indicator metrics covering hazard proximity and land use, health risk and exposure, and social and health vulnerability. A recent paper by Wilson et al. (2010) calculates vulnerability scores at the county level using data on race/ethnicity and socio-economic status, pollution sources and levels, and health. Similarly, the Environmental Justice Strategic Enforcement Assessment Tool (EJSEAT) was designed to enable the U.S. Environmental Protection Agency (EPA) to identify communities or areas that are susceptible to experiencing disproportionate environmental and public health burdens and is based on 18 individual variables collected at the census tract level (USEPA 2010).

Cutter et al. (2003) developed the SoVI as a way to quantify social vulnerability using county-level socio-economic and demographic data. The index comprises 42 variables which are reduced to 11 independent factors that are then used to compute a summary score. Oxfam (2009) applied SoVI in an analysis to identify counties in the Southeastern U.S. that are hotspots of high social vulnerability, then overlaid these data in a mapping tool with projections of climate change, including drought, floods, hurricane-force winds, and SLR. However, this study did not include consideration of the costs of adaptation to climate change risks, as we do here for SLR risks. Schmidtlein et al. (2008) published a paper testing the sensitivity of SoVI to different aggregation levels of the census data, including tract-level data. Given that coastal counties in the U.S. can contain highly variable levels of vulnerability to SLR inundation, an application at a finer level of census resolution (i.e., tract level instead of county) is more appropriate for the objectives of our analysis. ${ }^{2}$

\subsection{Description of approach used for estimating social vulnerability}

After reviewing the available literature on EJ indices, we determined that SoVI is best suited for this analysis. Our reasoning is that the index has been applied extensively by others (Borden et al. 2007; Schmidtlein et al. 2008; Burton and Cutter 2008; Wood et al. 2010), and because it is a pure social vulnerability index that does not include any environmental risk factors, including the coastal risks which we model explicitly using the NCPM. For example, an index that includes climate change risks in the vulnerability score (Moss et al. 2001) might present issues of effectively double counting climate risk when this information is combined with detailed data on SLR vulnerability. In our work, we also find that a rigorous separation of climate and socioeconomic vulnerability allows us to make a clearer distinction between those factors which can

\footnotetext{
${ }^{2}$ Certain census data is available only at the county level, so use of tract-level data implies that the analysis would not use the full 42 variables employed at the county level, but would instead rely on a reduced set of 26 variables, as evaluated in Schmidtlein et al. (2008).
} 
be affected by climate policy (the degree of greenhouse gas mitigation, which in turn influences the rate of SLR, and the adaptation response, which involves decisions of policy-makers), and those policies that make up a "baseline" social vulnerability (mainly, indicators of socioeconomic status). Without that clear separation of climate and social vulnerability, the issue of causality can be muddied - in other words, is the region vulnerable because of climate risks, or because of pre-existing socio-economic status? We wish to identify coastal areas inhabited by socially vulnerable populations because we believe they may have less capacity and resources over time to make necessary investments to protect development from coastal hazards.

As described in the next section, our approach seeks to reduce this uncertainty and improve modeling accuracy by separating the calculation of socio-economic risk and vulnerability to climate change, in this case SLR. As described in further detail below, we do this in three steps: calculating SoVI scores for each coastal census tract, estimating SLR risks and likely adaptation responses across a range of scenarios, and spatially comparing these two sets of information.

We chose to construct SoVI at the census tract level closely following the work of Schmidtlein et al. (2008). SoVI construction is a four-tiered process: (1) collect and clean input data, (2) standardize input data; (3) conduct principal components analysis (PCA); and (4) place the components in an additive model.

In the first step, we collected census tract level data for 26 demographic variables from the U.S. Census Bureau's American Fact Finder website. For purposes of applying SoVI and categorizing data in this analysis, we assign coastal counties in the contiguous U.S. to one of four regions: North Atlantic (Maine through Virginia), South Atlantic (North Carolina through Monroe County, Florida), Gulf(Collier County, Florida through Texas), and Pacific (California through Washington). Census tracts with populations reported as zero are omitted from the analysis. Where census tracts are missing data for a particular variable, we replace the missing value with the mean value for the region. ${ }^{3}$ Next, all input variables were standardized to $\mathrm{z}$ scores with zero means and unit variances. ${ }^{4}$ The input variables are standardized to avoid potential problems that may arise from using variables of different magnitudes in PCA.

The z-scores for each of our 26 variables are then used in PCA to reduce the variables to a smaller set of components. The resulting components are linear combinations of correlated variables that represent a broader measure of how certain components contribute to vulnerability. ${ }^{5}$ Component values are calculated for each census tract by multiplying a variable's

\footnotetext{
${ }^{3}$ There are 21,990 census tracts in the coastal counties of the contiguous U.S. Of these, $116(0.53 \%)$ had population reported as zero and were omitted from the analysis. $128(0.59 \%)$ of the remaining 21,874 tracts were missing data for one or more of the variables used to calculate SoVI - missing values were replaced with the mean value in the region. A potential issue is the use of current data to evaluate SLR risks that will manifest over several decades - put another way, communities that are socially vulnerable today may or may not be vulnerable in the future, as demographics change. As a result, it is difficult to assess whether future SLR damages might fall disproportionately on the most vulnerable communities. In most cases, however, adaptation actions for SLR must be planned well in advance of the manifestation of SLR threats to be most effective. As a key focus of this work is to identify socially vulnerable communities in need of near-term assistance to enhance adaptive capacity, we feel that the use of current demographic data may be less of an issue with our approach. Further, as a practical matter, long-term forecasts of detailed demographics are not currently available.

${ }^{4} \mathrm{Z}$-scores were derived by subtracting the mean of the study area - in this case the North Atlantic, South Atlantic, Gulf, or Pacific region - from the census tract value, then dividing this difference by the standard deviation for the study area.

${ }^{5}$ Following the previously published literature on SoVI, we use the Kaiser criterion (eigenvalues greater than 1.0) to select the set of factors which are used to construct the index. After the components are selected, we rotate the solution using a varimax rotation to make the results easier to interpret. The varimax rotation results in uncorrelated components and tends to maximize the variance of a single component. Following Wood et al. (2010), we considered component loadings to be meaningful at 0.5 and higher or -0.5 and lower.
} 
value by the estimated weight for the component. ${ }^{6}$ The PCA for the North Atlantic region produces a total of seven components, which explain $71 \%$ of the variance among the census tracts in that region. The PCA for the Gulf region also produces a total of seven components explaining $73 \%$ of the variance. The PCA for the South Atlantic and Pacific regions each produce six components explaining 71 and $68 \%$ of the variance, respectively. ${ }^{7}$ Table 1 presents the components and their associated variance explained and dominant variable for each regional PCA.

Once the components were derived, we made adjustments to their directionality based on their known influences on vulnerability. A positive directionality was assigned to components believed to increase vulnerability (e.g., poverty), while a negative directionality was assigned to components believed to decrease vulnerability (e.g., wealth). The components were then placed in an additive model where each component is assigned an equal weight. ${ }^{8}$ This additive model generates the overall SoVI score for each census tract. Following Schmidtlein et al. (2008), we standardized the resulting SoVI values to z-scores. This standardization is an important step that allows for comparative interpretations of the final SoVI scores for each area. For this analysis, we preformed the standardization at the U.S. regional level: North Atlantic, South Atlantic, Gulf, and Pacific.

An alternative to using an index to identify disadvantaged communities would be to simply analyze various demographic indicators using census data, such as wealth and race. We conducted a preliminary analysis using census block group level data, however we determined that this approach is less useful for spatially-comprehensive climate change impact assessment models, like the NCPM, because SoVI provides an analytically rigorous tool that combines multiple measures of social vulnerability in a single index value.

\subsection{Estimating vulnerability to SLR}

To estimate human response to the threat of SLR and the economic impacts on coastal property, we apply the NCPM. This framework employs GIS to structure and overlay available data (including coastal elevations and parcel-level property value data) using a 150-meter grid cell network covering the contiguous U.S. coastline. The model combines elevation data ${ }^{9}$ with SLR and sub-regional land subsidence rates to identify inundation risk information along the coast. The tool then models a response to the SLR threat over time, and reports estimates of response mode, property at-risk, property damages, and costs of adaptation in both graphical (map and chart) and tabular form. Protection decisions are determined on a grid cell basis according to calculations which compare the value of the land to the cost of various protection

\footnotetext{
${ }^{6}$ Weights for each component/region combination are available from the authors upon request.

7 These results are in line with previously published SoVI analyses. For example, the census tract-level SoVI analysis conducted in Schmidtlein et al. (2008) has a percent variance explained of 73.2.

${ }^{8}$ The equal-weighting of components approach is used in the original application of SoVI (Cutter et al. 2003) and has been used in subsequent applications of the index. Sensitivity of SoVI to the equal-weighting assumption is explored in Schmidtlein et al. (2008). The authors find that the manner in which the components are combined to create the final index does have a substantial impact on the end results, but they make no alternative weighting recommendation.

${ }^{9}$ For this national-scale application, we used $30 \mathrm{~m}$ digital elevation modeling, available from United States Geological Survey, and calibrated to a zero elevation (year 2000) as represented by the mean spring high water mark. Estimated tide ranges and sea level trends by the National Ocean Service helped determine the height of spring high water.
} 
Table 1 Components for each regional analysis in the contiguous United States. The table displays the Social Vulnerability Index components, including the dominant variables and their associated variance explained for each regional principle components analysis

\begin{tabular}{|c|c|c|c|c|c|c|c|}
\hline \multicolumn{2}{|c|}{ North Atlantic } & \multicolumn{2}{|l|}{ South Atlantic } & \multicolumn{2}{|l|}{ Gulf } & \multicolumn{2}{|l|}{ Pacific } \\
\hline Component & $\begin{array}{l}\text { Percent } \\
\text { Variance } \\
\text { Explained }\end{array}$ & Component & $\begin{array}{l}\text { Percent } \\
\text { Variance } \\
\text { Explained }\end{array}$ & Component & $\begin{array}{l}\text { Percent } \\
\text { Variance } \\
\text { Explained }\end{array}$ & Component & $\begin{array}{l}\text { Percent } \\
\text { Variance } \\
\text { Explained }\end{array}$ \\
\hline Poverty & 22.5 & Poverty & 20.3 & Poverty & 22.4 & Poverty & 21.6 \\
\hline $\begin{array}{l}\text { Rural/ } \\
\text { Urban }\end{array}$ & 11.4 & $\begin{array}{l}\text { Family } \\
\text { structure }\end{array}$ & 17.5 & $\begin{array}{l}\text { Labor force } \\
\text { participation }\end{array}$ & 16.6 & $\begin{array}{l}\text { Age } \\
\text { (children) }\end{array}$ & 13.1 \\
\hline $\begin{array}{l}\text { Age } \\
\text { (elderly) }\end{array}$ & 10.5 & Rural/Urban & 11.4 & Foreign-born & 12.3 & Rural/Urban & 11.7 \\
\hline $\begin{array}{l}\text { Foreign- } \\
\text { born }\end{array}$ & 8.8 & Foreign-born & 10.0 & Wealth & 8.2 & $\begin{array}{l}\text { Labor force } \\
\text { participation }\end{array}$ & 8.7 \\
\hline $\begin{array}{l}\text { Age } \\
\text { (children) }\end{array}$ & 7.4 & $\begin{array}{l}\text { Native } \\
\text { American/ } \\
\text { Female }\end{array}$ & 6.6 & Rural/Urban & 5.6 & Female & 7.5 \\
\hline Occupation & 5.4 & Occupation & 4.8 & Occupation & 4.4 & Occupation & 5.6 \\
\hline Female & 5.0 & & & Female & 4.0 & & \\
\hline
\end{tabular}

measures to determine an economically efficient response for each cell. Property value is assigned to grid-cells based on parcel level assessed value data, which is available in electronic form in many counties and regions of the U.S. Where the cost of protective measures is less than the benefit of avoided property value loss, the impact of SLR is estimated as the capital cost of seawall construction plus ongoing maintenance costs - in areas with beach frontage, maintenance of the existing beach profile is achieved through periodic beach nourishment, the cost of which is evaluated through estimates of sand volume required and a fixed cost per unit of sand. All cost estimates are consistent with those estimated from an analysis of U.S. Army Corps of Engineers beach protection projects. Where the cost of protection exceeds the benefit, retreat/abandonment is the estimated response, and the impact of SLR is lost structure and land value. In general, the model estimates that high-value land will be protected with hard structures or nourished with sand, while low-value land will be abandoned. The model estimates a trajectory of response to SLR through the 21st century, for each potentially threatened grid cell, based on scenarios of SLR over the same period. Thus while the algorithm for estimating response is relatively straightforward, the spatial dataset is very large, and the result is a highly-spatially resolved and differentiated estimate of areas threatened by SLR and the likely mode and cost of the adaptation response, which can be regenerated for a wide range of scenarios and input data to support uncertainty and sensitivity analyses. See Neumann et al. $(2010 \mathrm{a}, \mathrm{b})$ for more detailed discussions of the model.

We acknowledge that many decisions of this type in the coastal zone are not made with strict cost-benefit decision rules, particularly at the local level. Other factors may include local zoning bylaws, future land use plans, the presence of development-supporting infrastructure, or proximity to sites with high cultural value. However, the analytical framework of the NCPM provides a good indication of areas which, for example, might be supported in adaptive measures by the U.S. Army Corps of Engineers, which requires benefit-cost 
analyses to support, and in many cases justify, coastal infrastructure and beach nourishment projects. $^{10}$

The NCPM is capable of simulating a wide range of SLR trajectories through 2100. For this application, we applied three scenarios, with rates of SLR derived from MAGICC ${ }^{11}$ modeling (Wigley 2008) and Rahmstorf (2007):

1. Low scenario, which is based on MAGICC processing of an IPCC B1 ${ }^{12}$ scenario implying $28.5 \mathrm{~cm}$ SLR by 2100 compared to 1990 levels. $^{13}$

2. Mid scenario, also based on MAGICC processing, but of the IPCC A1B scenario, implying $66.9 \mathrm{~cm}$ SLR by 2100 compared to 1990 levels. $^{14}$

3. High scenario, based on Rahmstorf (2007) maximum, and implying $126.3 \mathrm{~cm} \mathrm{SLR}$ by 2100 compared to 1990 levels.

We apply our analytical framework to estimate adaptation costs for areas in the U.S. affected by Atlantic, Gulf, and Pacific coastal risks, but excluding Alaska, Hawaii, and island territories. The model forecasts which grid cells are likely to be abandoned, protected, and nourished in response to the threat of inundation from SLR. Where a cell straddles two or more block groups, that cell is assigned to the cell's predominant block group (and by extension, that cell's predominant tract). This information is then used in conjunction with SoVI to analyze the overlay of social and environmental vulnerability in coastal areas.

We note that the results presented in this analysis are calculated using estimates of the timing of inundation that are based on gradual changes in sea level. A key limitation at this stage of the research is that we do not assess how storm surge would affect the timing of inundation, and therefore, the decision of whether protection is warranted. However, the framework of the coastal property model is suitable to such an analysis, and efforts are underway to build capacity in the model to estimate damages from storms, and joint impacts of storms and SLR. Integration of risks from storm surge flooding will address many of the important impacts described in Kirshen et al. (2008), which indicate that the projected decrease in return frequency of coastal storms will have large effects on flood damages in the Northeastern U.S. Another important limitation is that we rely on current data for the socio-economic status and location of disadvantaged populations. Over the 21 st century, as climate change unfolds, it is reasonable to expect that populations will migrate, and incomes to grow or, in some cases, fall. Unfortunately, we have not identified a reliable approach to estimating migrations and income changes over the long time scales in which climate change and SLR will manifest.

\section{Results}

Nationally, our analysis finds that many socially vulnerable communities fall within the coastal zone that is at risk of SLR. While $9 \%$ of the land area and $4 \%$ of the population at

\footnotetext{
${ }^{10}$ See, for example, http://www.csc.noaa.gov/beachnourishment/html/human/socio/part2.htm for information on benefit-cost analyses conducted for beach nourishment projects.

${ }^{11}$ MAGICC is the "Model for the Assessment of Greenhouse-gas Induced Climate Change" and is a coupled gas-cycle/climate model. The IPCC used MAGICC as a primary model to project future increases in global mean temperature and sea level rise for the Third Assessment Report.

${ }^{12}$ See IPCC's Special Report on Emission Scenarios (http://www.ipcc.ch/ipccreports/sres/emission/index. $\mathrm{php}$ ? idp=0) for more information regarding the storylines behind emission scenarios B1 and A1B.

${ }_{13}$ MAGICC scenario assumed mid-range ice melting and $2{ }^{\circ} \mathrm{C}$ climate sensitivity.

${ }^{14}$ MAGICC scenario assumed high ice melting and $4.5^{\circ} \mathrm{C}$ climate sensitivity.
} 
risk of SLR is in the highest social vulnerability category, a total of $22 \%$ of the population (almost 750,000 people) and $46 \%$ of the land area (more than $6,700 \mathrm{sq} \mathrm{km}$ ) at risk is in the highest and second highest social vulnerability categories. The U.S. South Atlantic and Pacific regions have smaller areas and fewer socially vulnerable individuals at risk $(125,000$ individuals in the South, and 35,000 in the Pacific), but more than half the population at risk, almost 400,000 in the highest and second highest vulnerability categories, is in the U.S. Gulf region. Figure 1 presents the SoVI results, by area, for the Gulf Region. Much of the Florida Gulf coast is home to less socially vulnerable populations, while the southern Texas coast houses a majority of the most socially vulnerable populations in the Gulf. The second highest category of social vulnerability is widespread throughout coastal counties in the states of Texas, Louisiana, Mississippi, and Alabama, although most of these areas tend to have lower-density coastal development. The North Atlantic region, by contrast, is very densely populated, and so while it contains relatively small areas of high social vulnerability, these 'pocket' areas are home to a relatively large number of individuals - approximately 200,000 - of whom are both socially vulnerable and reside in areas of high SLR risk.

How these communities at risk of SLR impacts might respond to that risk is the key feature of the NCPM and a distinguishing factor in our analysis of social vulnerability relative to others in the literature. In effect, areas at risk of SLR, but with low levels of social vulnerability, should be able to effectively respond to this risk by fortifying shores or nourishing beaches, while more socially vulnerable populations would be more likely to have fewer resources within their communities to respond in this manner.

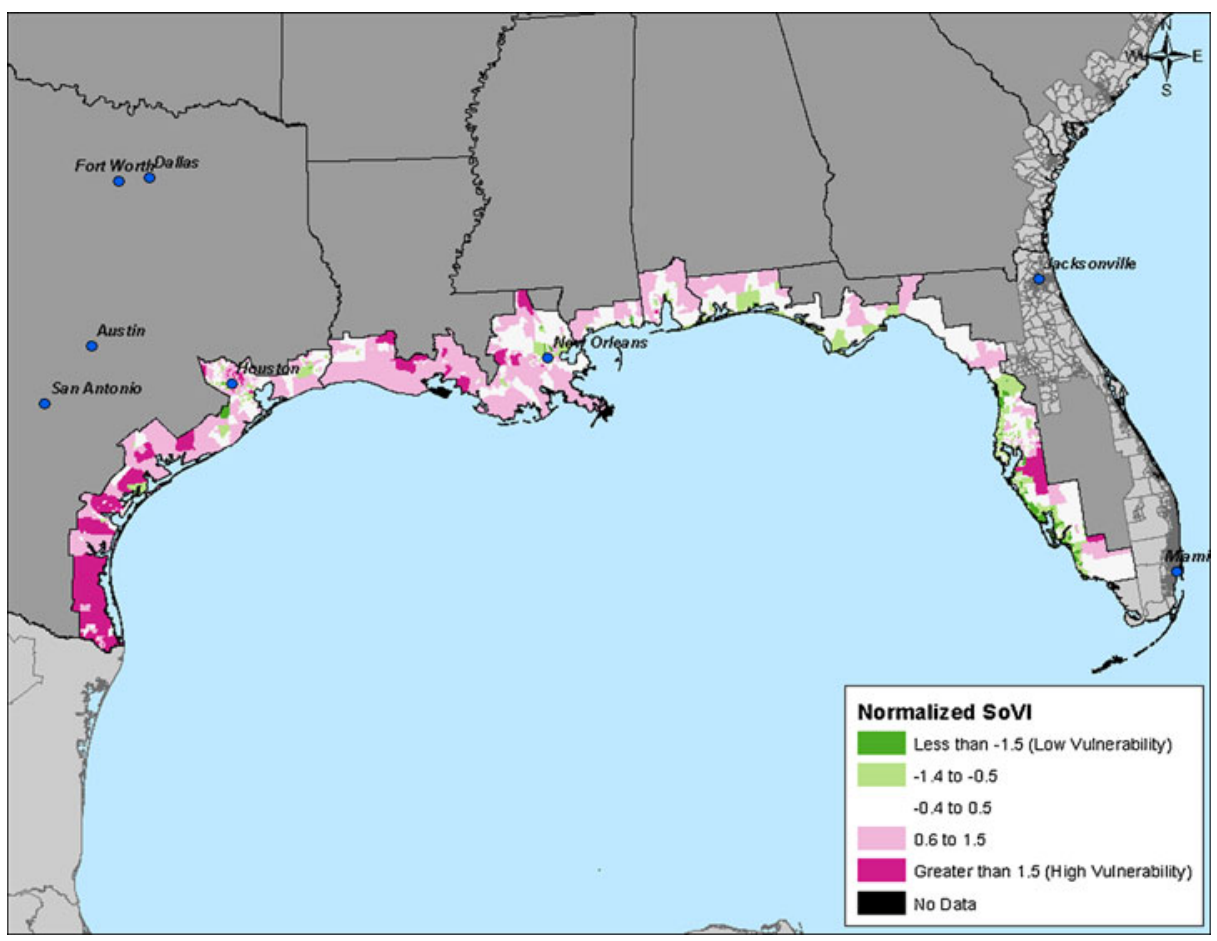

Fig. 1 Social vulnerability index results for the Gulf region of the United States. The less vulnerable areas (less than -0.5 standard deviations from the mean) are depicted in green and the more vulnerable areas (greater than 0.5 standard deviations from the mean) are depicted in pink 
Our results show exactly this expected pattern - Fig. 2 presents the area abandoned, armored, and nourished under the mid-SLR scenario for each SoVI category as well as the population located within each of these areas. We find that more land area is likely to be abandoned than protected in the higher social vulnerability categories. On the other hand, in the lower social vulnerability categories we find that more area is likely to be protected than
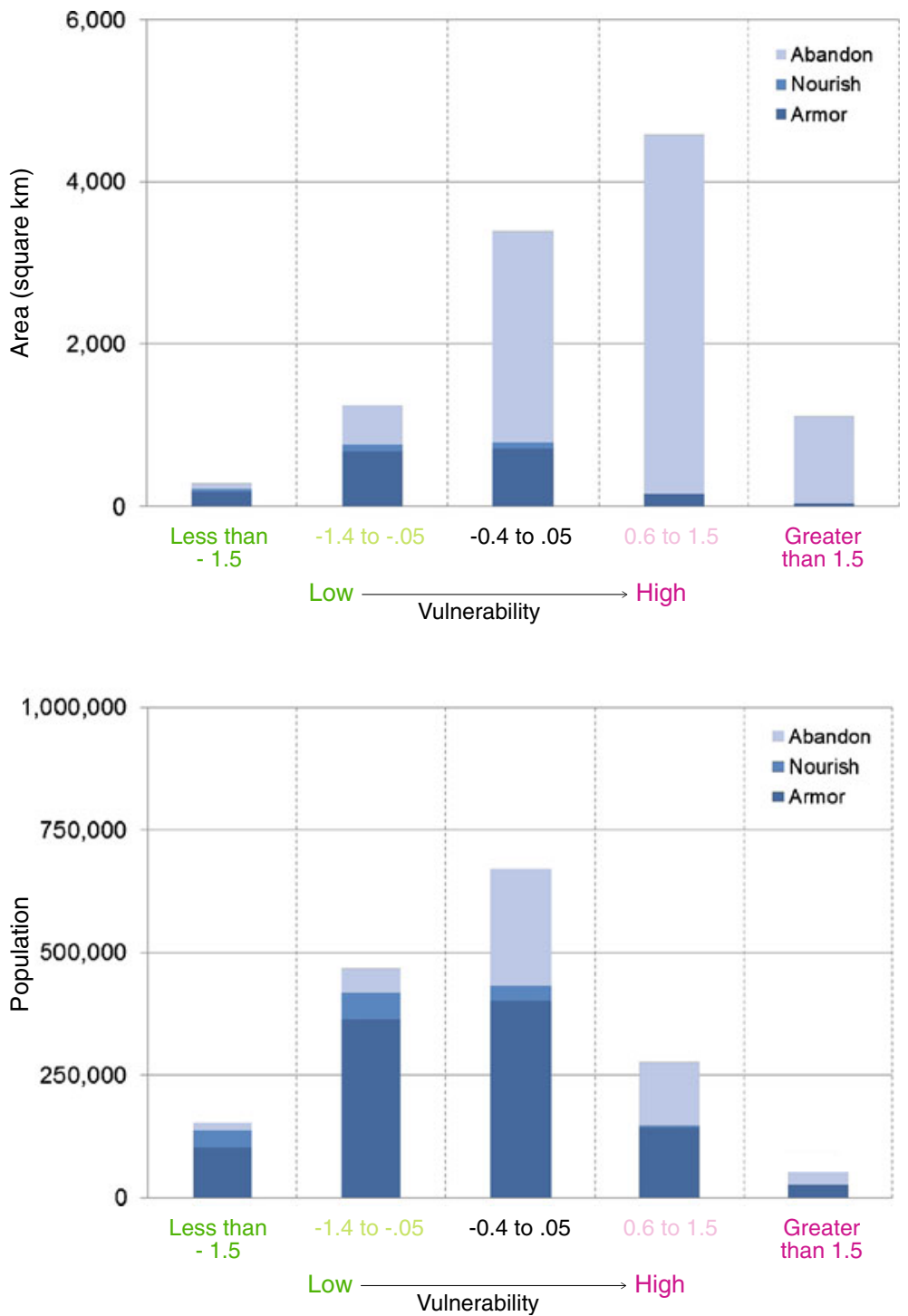

Fig. 2 Adaptation responses and social vulnerability for the contiguous United States. The total area and population abandoned, nourished, and armored are displayed under a mid-sea level rise scenario $(66.9 \mathrm{~cm})$ by Social Vulnerability Index score. Moving from left to right along the bar chart demonstrates that as social vulnerability increases, the area and population protected from sea level rise risk (armored and nourished) decreases while the area and population abandoned increases, relative to the total area at risk 
abandoned, consistent with the hypothesis that less socially vulnerable areas are likely to be protected and more socially vulnerable areas are likely to be abandoned.

When we consider population affected, rather than land area, the results are similar. A larger share of the population affected in the highest SoVI category is located in areas likely to be abandoned due to the threat of SLR. Across all SoVI categories, a greater share of the population will be protected than areas protected. Figure 3 presents the population within areas abandoned, armored, and nourished under each of the three SLR scenarios and conveys where these snapshots fit into the overall SLR trajectories. This exhibit shows that the pattern of population protected and abandoned by social vulnerability category holds across the three SLR scenarios. It is worth noting that as SLR increases across the three scenarios, the total population affected, total area affected, and total costs (protection costs, and property losses due to abandonment) increase considerably.

Figure 4 depicts the regional differences in the population results for the mid-SLR scenario. The population in areas abandoned in the highest three SoVI categories is greater than half of the total potentially affected population; in the highest SoVI category nearly all of the people affected by SLR could be compelled to abandon their property, if cost-benefit considerations dominate the decision. As noted above, benefit-cost criterion may not always be applied to protection decisions, but the benefit-cost comparison used in the NCPM does provide a consistent decision rule for identifying areas where economic considerations

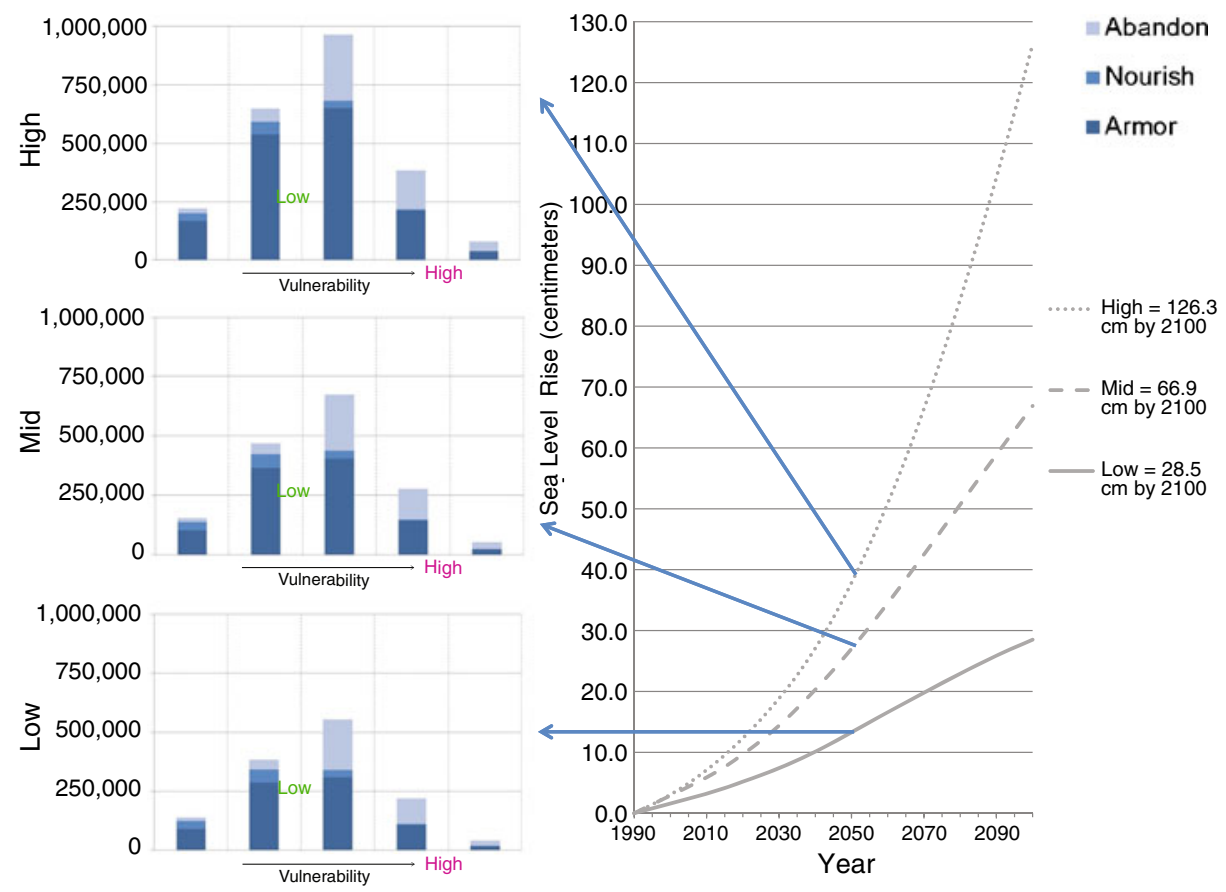

Fig. 3 Population by adaptation response and social vulnerability across low, mid, and high sea level rise scenarios. The population within areas abandoned, nourished, and armored is displayed under the low, mid, and high sea level rise scenarios by Social Vulnerability Index score. As sea levels rise, the population affected increases and the pattern across social vulnerability categories persists, with a larger share of the population residing in areas abandoned as social vulnerability increases 


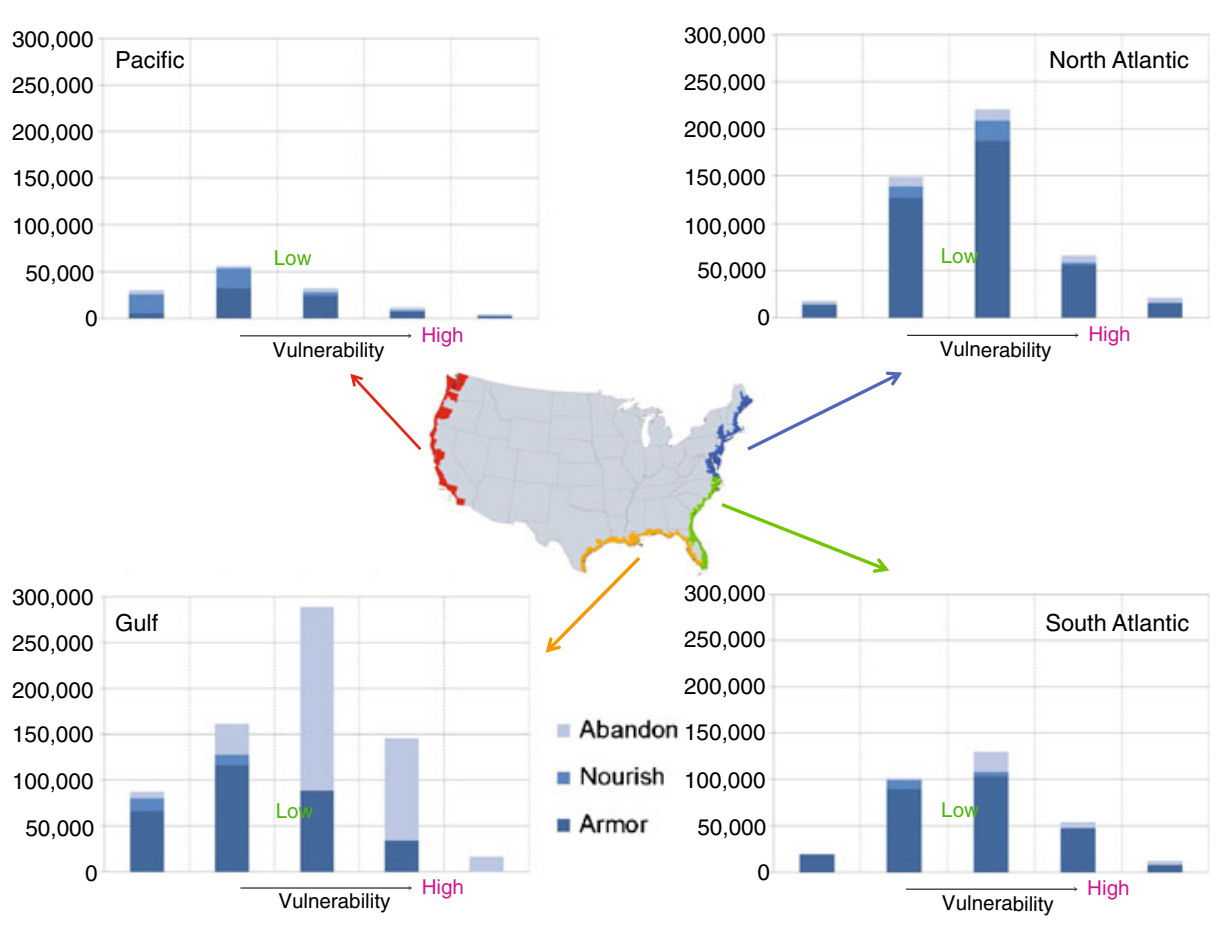

Fig. 4 Regional population by adaptation response and social vulnerability. The regional population abandoned, nourished, and armored are displayed under a mid-sea level rise scenario $(66.9 \mathrm{~cm})$ by Social Vulnerability Index score. This figure shows striking regional differences across the contiguous United States. Overall, a greater number of people are at risk of sea level rise in the Gulf and North Atlantic Regions, while less are at risk in the Pacific and South Atlantic Regions. The Gulf region has the largest population at risk of sea level rise and also the largest population located in areas that are likely to be abandoned in response to the threat

suggest protection and abandonment outcomes. As discussed below, this result highlights the need to consider factors other than just economic efficiency in coastal adaptation decision-making.

Using the GIS mapping capability of the NCPM, SLR risks and SoVI scores can be overlaid in the creation of maps. Figure 5 shows four examples of areas that are at high risk of SLR impacts and have high social vulnerability from each national study region. Areas similar to those shown in Fig. 5 can be found all along the coast - the examples given are meant to be representative. Many of the socially vulnerable areas at risk of SLR fall within agriculturally reliant communities, such as those east of the city of San Francisco, California, and along the Chesapeake Bay in the state of Maryland. Other socially vulnerable areas at risk are located in close proximity to major low-lying coastal cities such as New Orleans, Louisiana and Miami, Florida. In many locations, such as those surrounding New Orleans, San Francisco, and Miami, areas surrounding inland water bodies and wetlands are at risk of SLR in addition to the more commonly vulnerable areas along the coast.

As a comparison to the SoVI approach, we also identified disadvantaged communities by analyzing various demographic indicators using U.S. census data and combining this with SLR vulnerability information similar to the method applied with the SoVI scores. This simpler approach shows distinct patterns similar to the SoVI application - as expected, areas 

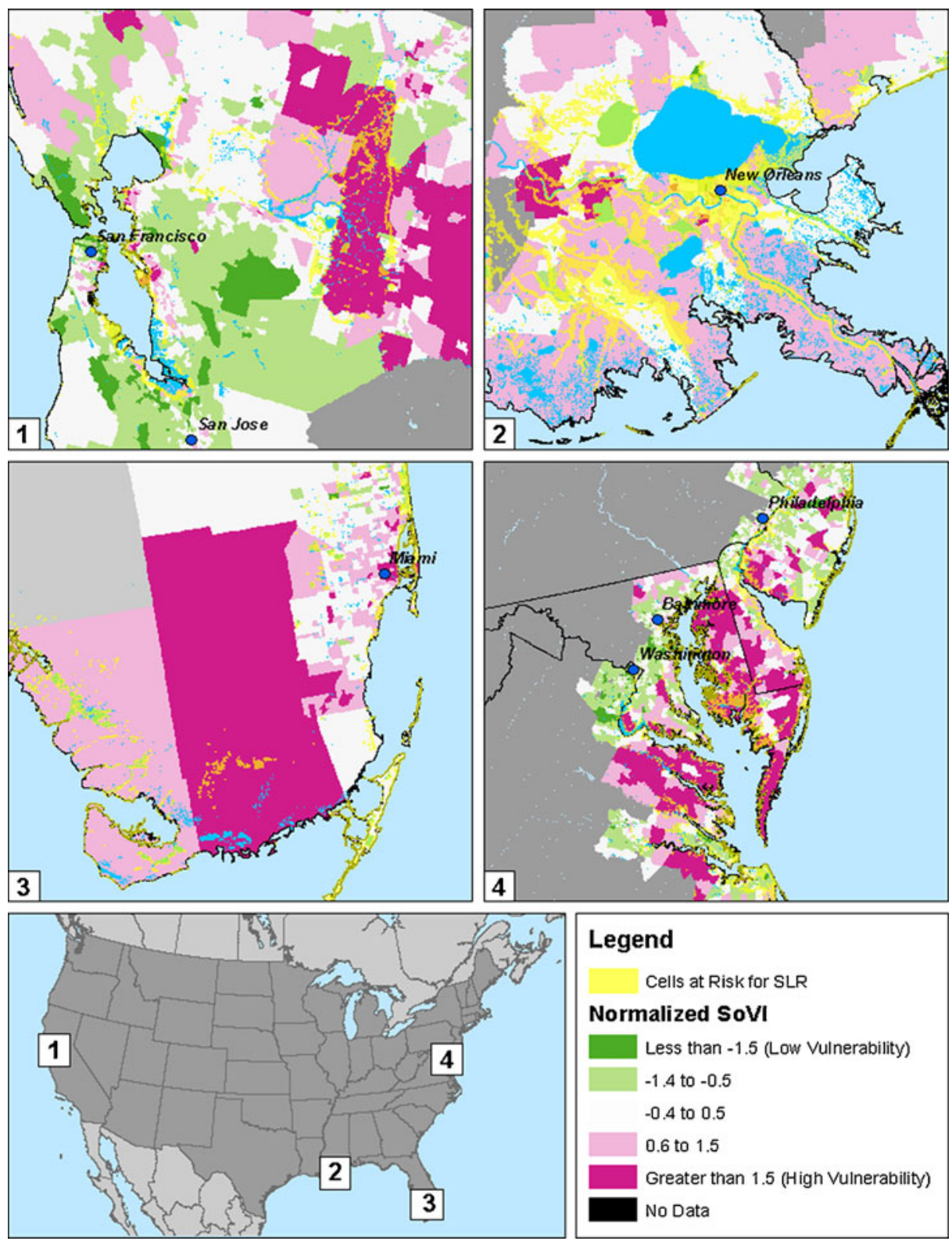

\section{Legend \\ Cells at Risk for SLR \\ Normalized SoVI

Less than -1.5 (Low Vulnerability)
-1.4 to -0.5
-0.4 to 0.5
0.6 to 1.5
Greater than 1.5 (High Vulnerability)
No Data

Fig. 5 Exemplary sea level rise risk areas with high social vulnerability. The areas at risk from a mid-sea level rise scenario $(66.9 \mathrm{~cm})$ are shown in yellow. Note that in this exhibit, cells are assumed to be at risk of sea level rise under a scenario that does not allow for adaptation. More cells are at risk here than under a scenario that does allow for adaptation, because cells with an armored-response provide protection for cells located inland

with lower property values do not receive protection in the NCPM because the cost of armoring or nourishing is greater than the value of property protected. However, the results are limited in terms of identifying specific areas that might be a focus for special consideration as a 
result of EJ concern, such as support for risk mitigation measures or relocation. This secondary method of using demographic indicators suggests that a more refined tool, such as SoVI, is needed to combine multiple measures of social vulnerability and more easily identify target areas for risk reduction and adaptation assistance.

\section{Discussion}

The results of this analysis indicate that many socially disadvantaged Americans living in coastal areas are very likely to be disproportionately affected by SLR. Our methodology can be used to identify geographic areas along the coast where socially disadvantaged communities are vulnerable to rising seas. In addition, we can project whether these communities are more likely to abandon their homes because protection from permanent inundation is not economically warranted.

These results are useful for coastal managers responsible for protecting coastal development and infrastructure, as these individuals will likely base their decisions on information regarding areas and populations that are most vulnerable to SLR. Our results are also useful to inform climate change policy discussions at domestic and international scales. While there have been significant research efforts focusing on the distributional and equity aspects of greenhouse gas mitigation policies, such as carbon taxes and revenue redistribution schemes (BEJEAP 2010), there has been less focus on distributional implications of impacts, and even less on distributional implications of adaptation actions.

Our approach addresses these policy needs in several ways. First, the ability to quantify SLR risks on coastal property, including how these risks are spread across socio-economic populations, provides information regarding the benefits of avoiding climate change through the mitigation of greenhouse gas emissions. Quantitative estimates of benefits that include these types of impacts are absent from most climate change policy dialogues in the U.S., and this knowledge is critical for communicating the merits of reducing these risks. This information is also important for informing decisions to balance investments in mitigation and adaptation, both in the U.S. and internationally, as this framework can be applied to coastlines around the globe with the availability of necessary data.

Second, the international community recognizes that large investments will be necessary over the course of this century for adapting to the effects of SLR, including the identification of those populations who are most vulnerable and have the least capacity to adapt. This remains one of the largest topics of discussion amongst nations participating in international negotiations to develop a climate treaty (UNFCCC 2011). Furthermore, numerous studies (e.g., Moser et al. 2008; Preston et al. 2011) have investigated the need and benefits of ensuring equitable access to resources that reduce climate change vulnerabilities and improve adaptive capacity. However, at domestic and international scales, there remains uncertainty regarding what areas should be prioritized for resource investment, and how EJ considerations will be handled in this decision-making process. Our approach is not prescriptive concerning how EJ considerations should be balanced with economic efficiency considerations, either in public sector or private adaptation investment decision making, as it seems clear that a societal consensus concerning the appropriate weight for equity and efficiency considerations has not been reached in either climate change policy or other contexts. We would argue, however, that the first important step in enabling consideration of EJ is generation of a consistent dataset to characterize socially vulnerable populations, relative to those risks that can be mitigated through policy action. Our method provides just such a measure. 
Finally, the execution of our approach has yielded several 'lessons learned' that we believe are important considerations for coastal zone managers and climate change policy analysts around the world. As described at the beginning of the Methods section, our analytical framework is sufficiently flexible to accommodate varying levels of data sophistication and availability. ${ }^{15}$ While we believe there to be substantial benefits to using advanced tools in this framework, such as the SoVI and the NCPM, the approach can be scaled to reasonably replicate the analysis for other coastlines in both developed and developing countries.

The first lesson learned is that mapping SLR risks in a spatially-comprehensive GIS with site-specific data lends itself to a wide variety of potential applications suitable for analysis at national, regional, and local levels. While we analyze EJ-related considerations in this paper, the mapping technology could also: (1) assess how storm surge events along the coast will enhance vulnerabilities to SLR and affect response decisions; (2) assess how SLR will affect coastal ecosystems, including the implications that these impacts will have on coastal development (e.g., loss of wetland buffer capacity for storm surge attenuation); and (3) analyze how land use planning strategies (e.g., easements) will drive response to SLR and associated costs. Second, we learned that indices, particularly ones that allow for the separation of climate and socio-economic vulnerability (e.g., SoVI), can be very useful tools for analyzing a large set of socio-economic and demographic variables. Finally, our analysis has shown that the consideration of EJ in coastal vulnerability analysis is important. Where traditional methods of planning for SLR generally do not factor EJ into the decisionmaking process, we hope that our paper will convince others to adopt approaches that consider this important issue.

\section{Conclusion}

Our analysis, and the analytical framework supporting it, serves as a substantial first step in obtaining the information necessary for answering complex policy questions regarding the benefits of climate change policy and the EJ implications of adaptation responses to SLR risks. Over the next century, all levels of governments around the world will be challenged with decisions of whether to invest in programs which target these vulnerable populations by providing resources to protect properties or help with relocation. With almost 6,000 square miles of area at risk of inundation in the U.S. under the mid-SLR scenario, and the value of coastal development vulnerable to SLR extending to just more than one trillion dollars in the U.S. alone (Neumann et al. 2010b), coastal protection decisions are likely to be complex and influenced by many competing factors. Our analysis quantitatively shows that EJ concerns should be an important consideration among these factors.

Open Access This article is distributed under the terms of the Creative Commons Attribution Noncommercial License which permits any noncommercial use, distribution, and reproduction in any medium, provided the original author(s) and source are credited.

\footnotetext{
${ }^{15}$ While we believe that our analytical framework is transferable to others, we recognize that quantitative analyses of SLR risks are limited in areas completely void of data. Our framework, like any other analytical model or tool, does require a certain level of data quality and integrity.
} 


\section{References}

BEJEAP (2010) A special issue on distributional aspects of energy and climate policy. Berkeley Elec J Econ Anal Pol 10(2)

Borden K, Schmidtlein M, Emrich C, Piegorsch W et al (2007) Vulnerability of U.S. cities to environmental hazards. J Hmlnd Sec Env Mgmt 4(2):1-21

Burton C, Cutter S (2008) Levee failures and social vulnerability in the Sacramento-San Joaquin Delta area, California. Nat Hzd Rev 9(3):136-149

CCSP (2009) Coastal sensitivity to sea-level rise: a focus on the Mid-Atlantic region. U.S. Climate Change Science Program, Washington, DC

Clark G, Moser S, Ratick S, Dow K et al (1998) Assessing the vulnerability of coastal communities to extreme storms: the case of Revere, MA, USA. Mit Adpt Strat Gl Chg 3(1):59-82

Cutter S (1996) Vulnerability to environmental hazards. Prog Hmn Geogr 20:529-539

Cutter S, Boruff B, Shirley W (2003) Social vulnerability to environmental hazards. Soc Sci Qrt 84(2):242-261

Dow K (1992) Exploring differences in our common future(s): the meaning of vulnerability to global environmental change. Geoforum 23(3):417-436

Hinkel J, Nicholls R, Vafeidis A, Tol R et al (2010) Assessing risk of and adaptation to sea-level rise in the European Union: an application of DIVA. Mit Adpt Strat Gl Chg 15(7):703-719

Karl T, Melillo J, Peterson T (eds) (2009) Global climate change impacts in the United States. Cambridge University Press, New York

Kirshen P, Watson C, Douglas E, Gontz A et al (2008) Coastal flooding in the northeastern United States due to climate change. Mit Adpt Strat Gl Chg 13:437-451

Kleinosky L, Yarnal B, Fisher A (2006) Vulnerability of Hampton Roads, VA to storm-surge flooding and sealevel rise. Nat Hzd 40:43-70

Memorandum of Understanding on Environmental Justice and Executive Order 12898, U.S. Government. Available via http://epa.gov/environmentaljustice/resources/publications/interagency/ej-mou-2011-08.pdf. Cited August 24, 2011

Moser S, Kasperson R, Yohe G, Agyeman J (2008) Adaptation to climate change in the Northeast United States: opportunities, processes, constraints. Mit Adpt Strat Gl Chg 13:643-659

Moss R, Malone E, Brenkert A (2001) Vulnerability to climate change: a quantitative approach. Prepared for the U.S. Department of Energy

Neumann J, Hudgens D, Herter J, Martinich J (2010a) Assessing sea-level rise impacts: a GIS-based framework and application to coastal New Jersey. Cstl Mgmt 38:433-455

Neumann J, Hudgens D, Herter J, Martinich J (2010b) The economics of adaptation along developed coastlines. Wiley Interdis Rev Cli Chg 2:89-98

Nicholls R et al (2007) Coastal systems and low-lying areas. In: Parry M et al (eds) Climate change 2007: impacts, adaptation and vulnerability. Contribution of Working Group II to the Fourth Assessment Report of the Intergovernmental Panel on Climate Change. Cambridge University Press, Cambridge

Nicholls R, Tol R, Vafeidis A (2008) Global estimates of the impact of a collapse of the West Antarctic ice sheet: an application of FUND. Cli Chg 91:171-191

NRC (2011) Climate stabilization targets: emissions, concentrations, and impacts over decades to millennia. National Research Council (NRC). The National Academies Press, Washington, DC

Oxfam America (2009) Exposed: social vulnerability and climate change in the U.S. Southeast. Available via http://adapt.oxfamamerica.org/resources/Exposed_Report.pdf. Cited August 24, 2011

Poastor M, Sadd J, Morello-Frosch R, Scoggins J (2009). Environmental justice screening method: integrating indicators of cumulative impact into regulatory decision-making. Developed for the California Air Resources Board. Available via http://college.usc.edu/pere/documents/revised_overview_tool_2009_10_08.pdf. Cited August 24, 2011

Preston B, Westaway R, Yuen E (2011) Climate adaptation planning in practice: an evaluation of adaptation plans from three developed nations. Mit Adpt Strat Gl Chg 16(4):407-438

Rahmstorf S (2007) A semi-empirical approach to projecting future sea-level rise. Sci 315:368-370

Rygel L, O’Sullivan D, Yarnal B (2006) A method for constructing a social vulnerability index: an application to hurricane storm surges in a developed country. Mit Adpt Strat Gl Chg 11:741-764

Schmidtlein M, Deutsch R, Piegorsch W, Cutter S (2008) A sensitivity analysis of the social vulnerability index. Rsk Anal 28(4):1099-1114

Titus J, Park R, Leatherman S, Weggel J et al (1991) Greenhouse effect and sea-level rise: potential loss of land and the cost of holding back the sea. Cstl Mgmt 19:171-204 
United Nations Framework Convention on Climate Change (2011) Report of the conference of the parties on its sixteenth session. Available at http://unfccc.int/resource/docs/2010/cop16/eng/07a01.pdf\#page=4. Cited August 24, 2011

U.S. Environmental Protection Agency (2010) The environmental justice strategic enforcement assessment tool (EJSEAT). Office of Enforcement and Compliance Assurance, accessed by http://www.epa.gov/ compliance/ej/resources/policy/ej-seat.html. Cited August 24, 2011

Vafeidis A, Nicholls R, McFadden L, Tol R et al (2008) A new global coastal database for impact and vulnerability analysis to sea-level rise. J Cstl Res 24(4):917-924

Wigley T (2008) MAGICC/SCENGEN version 5.3.v2: technical user manual. Available at: http://www.cgd. ucar.edu/cas/wigley/magicc/UserMan5.3.v2.pdf. Cited August 24, 2011

Wilson S, Richard R, Joseph J, Williams E (2010) Climate change, environmental justice, and vulnerability: an exploratory spatial analysis. Env Jstce 3(1):7-11

Wood N, Burton C, Cutter S (2010) Community variations in social vulnerability to Cascadia-related tsunamis in the U.S. Pacific Northwest. Nat Hzd 52:369-389

Yohe G (1990) The cost of not holding back the sea: toward a national sample of economic vulnerability. Cstl Mgmt 18:403-431

Yohe G, Neumann J, Marshall P, Ameden H (1996) The economic cost of greenhouse induced sea level rise in the United States. Cli Chg 32:387-410 